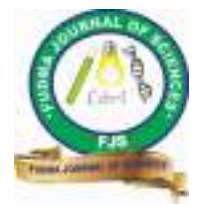

FUDMA Journal of Sciences (FJS)

ISSN online: $2616-1370$

ISSN print: 2645 - 2944

Vol. 4 No. 3, September, 2020, pp $192-196$

DOI: https://doi.org/10.33003/fjs-2020-0403-301

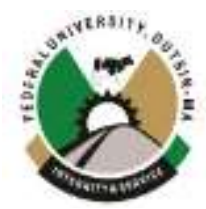

\title{
EVALUATION OF THERMAL STORAGE CAPACITIES OF SOME SELECTED MATERIALS FOR SOLAR DRYING APPLICATIONS
}

\author{
${ }^{1}$ Hassan, U., ${ }^{2}$ Adeleke, W. A., ${ }^{3}$ Mohammed, M., ${ }^{1}$ Adamu, M. A., and ${ }^{4}$ Sanusi, A. \\ ${ }^{1}$ Department of Mechanical Engineering, Ahmadu Bello University, Zaria, Nigeria \\ ${ }^{2}$ Department of Mechanical Engineering, Nile University of Nigeria, Abuja, Nigeria \\ ${ }^{3}$ Department of Mechanical Engineering Technology, Federal Polytechnic Kaura Namoda, Nigeria \\ ${ }^{4}$ Department of Civil Engineering, Nile University of Nigeria, Abuja, Nigeria
}

\begin{abstract}
This work aimed at evaluating the thermal storage capacities of granite grits, laterite rock, sand, laterite, and Clay for solar drying applications. The sample materials were ground and sieved through $0.425 \mathrm{~mm}$ British Standard sieve. The thermal conductivity, specific heat capacity, bulk density and melting point of the materials were determined. The results showed that Clay displayed better potentiality as thermal storage material with the highest thermal conductivity and specific heat capacity of $2.16 \mathrm{~W} / \mathrm{m}{ }^{\circ} \mathrm{C}$ and $1.398 \mathrm{~kJ} / \mathrm{kg} \mathrm{K}$ respectively. Laterite was observed to be the least with $1.07 \mathrm{~W} / \mathrm{m}^{\circ} \mathrm{C}$, and $0.499 \mathrm{~kJ} / \mathrm{kg} \mathrm{K}$ respectively. The Sand was observed to have higher bulk density compared with other sample materials while Laterite exhibited the lowest. The analysis of the result indicates that clay could be used as material for thermal energy storage facility in solar drying applications.
\end{abstract}

Keywords: Sensible heat storage, solar-drying application, and thermal-storage capacity.

\section{INTRODUCTION}

Sun-drying is the most common and widely known application of the energy harvested from the Sun. The sun intensity coupled with the air took a vital role in food preservation from thousands of years ago. In agricultural operation, solar thermal technology is one of the technologies that is briskly acceptable as an energysaving measure. It is recommended and a better option than wind, hydro, geothermal and other sources of energy because it is ample, indefatigable, inexhaustible, non-polluting and the most promising renewable energy source (Abdulelah et al., 2014).

In different places across the world, the solar thermal system is commonly used in an agricultural operation to preserve coffee, vegetables, fruits, and many other crops, it has shown to be a provident, practical and also responsible approach for a safer environment. Drying of food and other crops through solar heating can improve the quality of the product. Food processing technologists, scientists, and engineers concluded that reduction of moisture content of food, crops and other perishable agricultural product from $15 \%$ to $20 \%$ will improve their quality (Rajeshwari et al., 2012). The conventional ways of drying which are still applicable in the world till today is open sun drying by which crops, food, and other agricultural product are dispersed on the floor and carefully turned regularly until satisfied. However, the problems associated with such a conventional direct Sun drying method include losses due to attack by rodents, animals, rains, dust in addition to unhygienic end products (Hassan et al., 2018). To overcome such problems, foods' drying via solar dryers is the most effective and hygienic way which requires lesser space, time and is inexpensive compared to other artificial mechanical dryers.

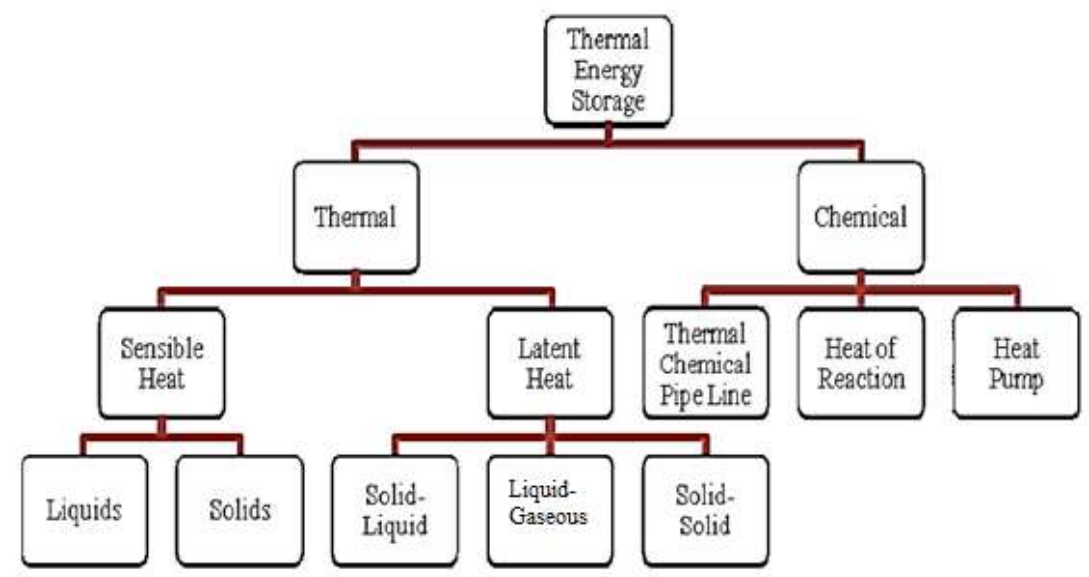

Figure 1: The forms of thermal energy storage (Karunesh et al., 2016) 
There are several pieces of research for solar drying systems focused on different design approaches, construction/fabrication techniques and the mode of operations. However, studies on the thermal energy storage capabilities of different materials used for the construction of such dryers are limited. Hassan et.al (2018) in their research showed that the maximum temperature in the drying chamber was observed at around 2:00 pm and then decreased at a fluctuated rate until the drying is completely stopped. This was as a result of reaching an equilibrium temperature between the inside and outside of the solar dryer. The main challenge of the solar dryer is the optimum utilization of the collected energy that could be possible only during the day. To conserve such excess energy resources, a means of storage facility that could be harvested at night is essential Karunesh et.al., (2016) described a solar dryer using thermal energy storage materials as an effective measure in providing continuous drying effect on the processed and unprocessed agricultural products at steady state in the temperature range $\left(40^{\circ} \mathrm{C}-60^{\circ} \mathrm{C}\right)$. Such dryers have globally become a potential viable substitute to the common solar dryers.

Therefore, this work intends to evaluate the thermal storage capacity of different materials. The work would determine the ability of the materials in storing the collected energy during the day and releasing it when the atmospheric temperature is low.

\section{METHODOLOGY}

This work involves the Identification and collection of potential thermal storage materials from Abuja. The materials were pretreated and ground into smaller particle sizes $(0.425 \mathrm{~mm})$ for a proper determination of their physical and thermal properties. Plate 1-5 are obtained materials in their compacted and powdered forms.

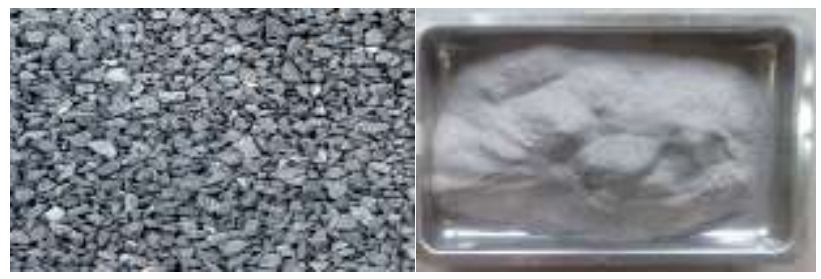

Plate1: Coarse Granite and its powder

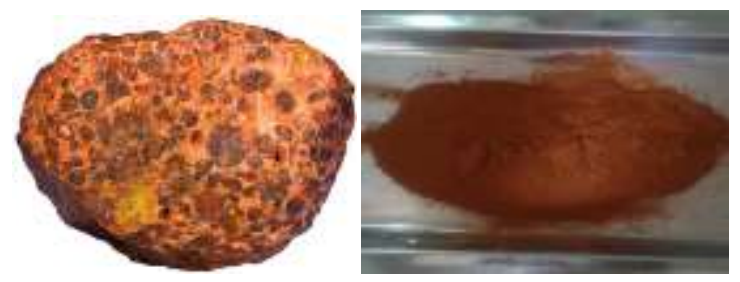

Plate 2: Laterite rock and its powder

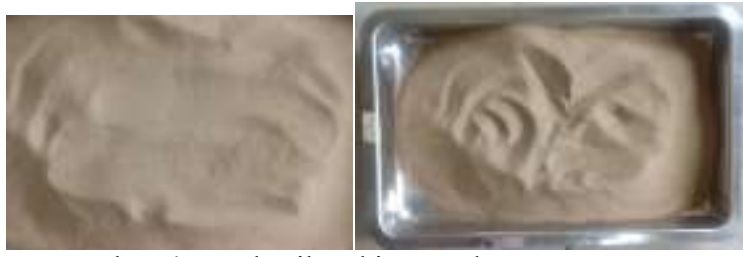

Plate 4: Sand soil and its powder

Plate 3: Laterite and its and its powder

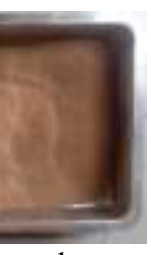

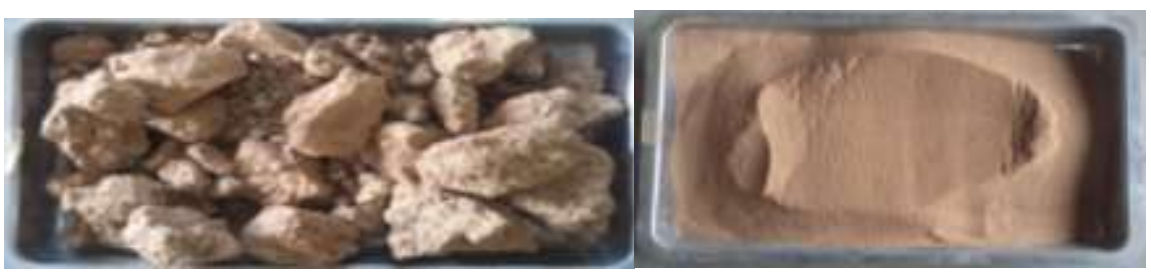

Plate 5: Clay soil and its powder

\section{Thermal Conductivity of the Materials}

The thermal conductivity test was carried out on all the five selected materials using the thermal conductivity apparatus in Plate 6 designed to function as described using equation (1) (Holman, 2010) $\mathrm{k}=\frac{\mathrm{q}\left(\mathrm{r}_{0}-\mathrm{r}_{1}\right)}{4 \pi \mathrm{r}_{0} \mathrm{r}_{1}\left(\mathrm{~T}_{1}-\mathrm{T}_{0}\right)}, \mathrm{W} / \mathrm{m}^{\circ} \mathrm{C}$

Where $q$ is the heat input in Watt; $r_{1}, r_{0}$ is the internal and external radius in metre and $T_{1}, T_{0}$ is the internal and external surface temperature in ${ }^{\circ} \mathrm{C}$ 


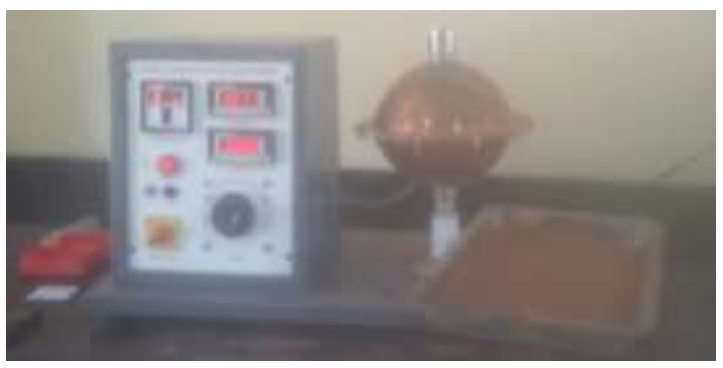

Plate 6: Thermal conductivity apparatus

\section{Bulk density of the Materials}

Bulk density test was carried out on all the materials with the aid of $3.05 \times 10^{-3} \mathrm{~kg} / \mathrm{m}^{3}$ bulk density cylinder, Scoop, weight scale, set of BS laboratory sieve and tamping rod. In the determination of the bulk density, the procedure in general engineering laboratory manual for engineering students by Adeleke et al., (2018) was adopted and equation 2 was used to calculate the average bulk density of the selected materials.

$$
\mathrm{D}_{\mathrm{b}}=\frac{(\mathrm{M} 2-\mathrm{M} 1)}{\mathrm{Vc}}, \mathrm{kg} / \mathrm{m}^{3}
$$

$\mathrm{M}_{1}$ is the mass of the container only; $\mathrm{M}_{2}$ is the combine masses of the materials and the container; $\mathrm{Vc}$ is the calibrated volume determined and $\mathrm{D}_{\mathrm{b}}$ is the Bulk density.

\section{Specific heat capacity test}

The specific heat capacity test was conducted following the procedure in (Adeleke, et al., 2018). In the procedure, 100g of the sample material was weighed using beam balance and recorded as $\mathrm{W}_{\mathrm{s}}$. The same mass of water also measured and poured into the calorimeter and recorded as $\mathrm{W}_{\mathrm{w}}$, while the initial temperature of water in the calorimeter was measured and recorded as $\mathrm{T}_{\mathrm{w}}$. The temperature of the materials was raised in a beaker to $80^{\circ} \mathrm{C}$ and recorded as $\mathrm{T}_{\mathrm{s}}$, the heated materials were added to the water in the calorimeter, the calorimeter was covered and stirred to have equilibrium temperature, the equilibrium temperature $T_{e}$ of the mixture of water and dry soil in calorimeter was recorded. The specific heat of the sample particles $\mathrm{C}_{\mathrm{s}}$ was determined from the equilibrium temperature as in equation 3

$\mathrm{C}_{\mathrm{s}}=\frac{\left(\mathrm{T}_{\mathrm{w}}-\mathrm{T}_{\mathrm{e}}\right) \times \mathrm{C}_{\mathrm{w}} \times \mathrm{W}_{\mathrm{w}}}{\left(\mathrm{T}_{\mathrm{e}}-\mathrm{T}_{\mathrm{s}}\right) \mathrm{W}_{\mathrm{s}}}, \mathrm{kJ} / \mathrm{kgK}$

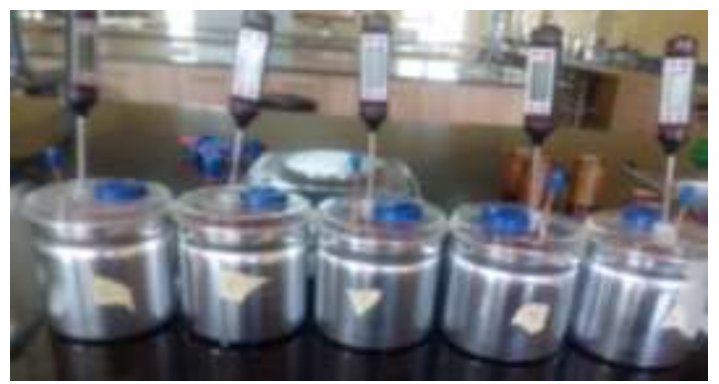

Plate 7: Specific heat capacity apparatus

Where; $\mathrm{T}_{\mathrm{w}}$ is the initial temperature of water in the calorimeter $\left({ }^{\circ} \mathrm{C}\right), \mathrm{T}_{\mathrm{s}}$ is the initial temperature of dry sample $\left({ }^{\circ} \mathrm{C}\right), \mathrm{T}_{\mathrm{e}}$ is the equilibrium temperature of mixed water and dry soil in the calorimeter $\left({ }^{\circ} \mathrm{C}\right), \mathrm{C}_{\mathrm{w}}$ is the specific heat of water $\mathrm{J} / \mathrm{kg} /{ }^{\circ} \mathrm{C}, \mathrm{W}_{\mathrm{w}}$ is the mass of water in the calorimeter $(\mathrm{kg})$, and $\mathrm{W}_{\mathrm{s}}$ mass of dry soil (kg).

\section{Determination of the Melting Point}

The melting point test was conducted following (Richard et al., 2009). In the method, the temperature at which the sample materials change phase from solid to liquid was targeted. However, the capacity of the melting point apparatus available was design accommodate a temperature $\leq 400^{\circ} \mathrm{C}$ which is lower than the melting point of the selected samples.

\section{DISCUSSION OF RESULTS}

The results in table 1 show that the highest thermal conductivity of $2.16 \mathrm{~W} / \mathrm{m}^{\circ} \mathrm{C}$ was achieved with Clay sample while Laterite sample has the least with $1.07 \mathrm{~W} / \mathrm{m}^{\circ} \mathrm{C}$. According to Reddy et al., (2019), the high thermal conductivity increases the thermal charging and discharging rate. The higher the thermal conductivity of the thermal storage materials, the lower the insulation of that material and is the better option. In terms of the average specific heat capacity of the materials, the same clay recorded highest with $1.398 \mathrm{~kJ} / \mathrm{kg} \mathrm{K}$ while laterite was also the least with $0.499 \mathrm{~kJ} / \mathrm{kg} \mathrm{K}$ as shown in figure 2 . The amount of heat stored depends on the specific heat of the materials, the temperature change, and the amount of storage material (Kumar et al., 2015) and High specific heat improves energy storage density of the system (Reddy et al., 2019). The melting points of all the sample materials are above $400^{\circ} \mathrm{C}$ suitable for both sensible heat and the latent heat storage.

Table 1: Results for the physical and thermal properties of the selected materials

\begin{tabular}{|l|l|l|l|l|l|}
\hline \multirow{2}{*}{ Properties } & \multicolumn{5}{|c|}{ Selected materials } \\
\cline { 2 - 6 } & Granite & Laterite & Sand & Laterite Rock & Clay \\
\hline & 1.47 & 1.07 & 1.21 & 1.17 & 2.16 \\
\hline $\mathrm{k}_{\mathrm{avg}}\left(\mathrm{W} / \mathrm{m}^{\circ} \mathrm{C}\right)$ & 1468.41 & 1093.44 & 1605.08 & 1442.13 & 1187.70 \\
\hline$\rho_{\text {avg }}\left(\mathrm{kg} / \mathrm{m}^{3}\right)$ & 0.627 & 0.499 & 0.546 & 0.559 & 1.398 \\
\hline
\end{tabular}

For bulk density, the highest value of $1605.08 \mathrm{~kg} / \mathrm{m}^{3}$ was obtained with Sand followed by Granite with $1468.41 \mathrm{~kg} / \mathrm{m}^{3}$, 
while Laterite has the lowest bulk density among the materials selected. Higher bulk density improves energy storage density which reduces the volume of the thermal energy storage system (Presley et al., 1996). Any further increase in the bulk density of these materials will lead to an increase in their thermal conductivity which will increase their thermal energy storage capacity.

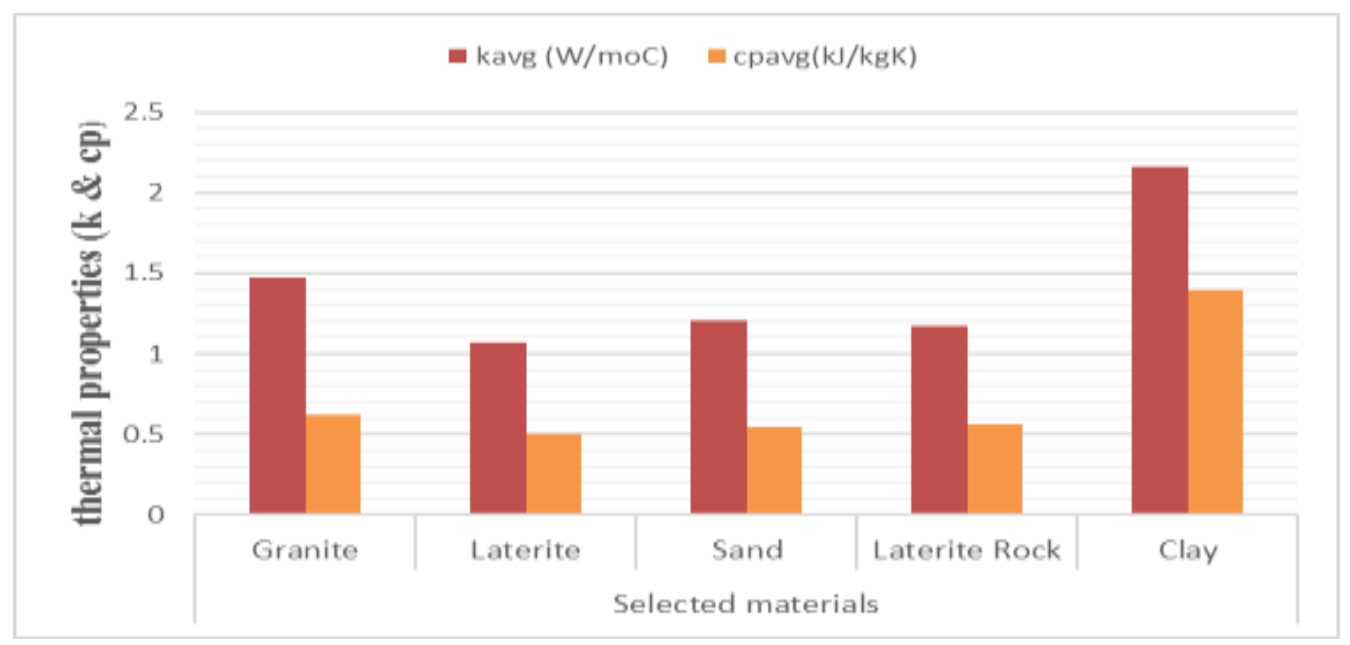

Figure 2: The graph of thermal conductivity and specific heat capacity against the materials

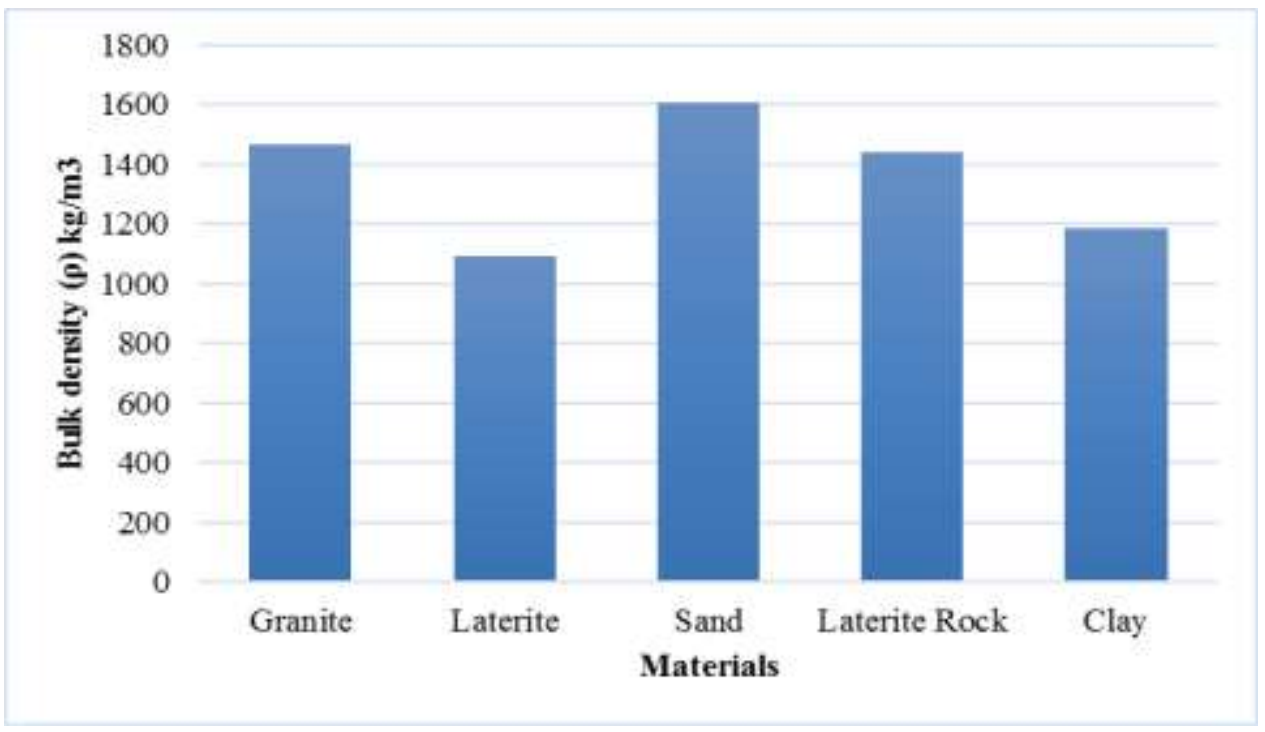

Figure 3: The graph of bulk density against the materials

\section{CONCLUSIONS}

Thermal conductivity, specific heat capacity, melting point, and bulk density tests were carried out on all the selected materials. The analysis of the result indicated that clay has better thermal properties (thermal conductivity and specific heat capacity) of $2.16 \mathrm{~W} / \mathrm{mK}$ and $1.398 \mathrm{~kJ} / \mathrm{kg} \mathrm{K}$ respectively as compared with other sample materials for thermal energy storage in solar drying applications followed by granite. The obtained result is inconsistent with the findings of Hasnain, (1998) who concluded that the most prevalent storage material is clay brick. However, for the bulk density of the selected materials, Sand has the highest density value which signifies an improved thermal energy storage density.

\section{REFERENCES}

Abdulelah, A. A., Abdullah, M. A., Mohamed, F. A. Ahmed, M. D. and Fahd, M. A. (2014).Design and construction of a solar drying system for food preservation. Mechanical Engineering Department, College of Engineering, Jazan University.

Adeleke, W.A., Paul, O., Sanusi, A., \& Ado, M. (2018). General Engineering Laboratory manual for engineering students. Nile University of Nigeria, Abuja. 
Hasnain, S. M. (1998). Review on sustainable thermal energy storage technologies, Part I: heat storage materials and techniques. Energy Conversion and Management, 39(11), 1127 1138. doi:10.1016/s0196-8904(98)00025-9

Hassan, U., Mohammed, Y., Umaru, S., Kulla, D.M., Adamu, M.A and Bello S.(2018). performance evaluation of solar fish dryer toward enhancing fish preservation in Nigeria. 8th annual $\&$ international conference journal of renewable \& alternative energy society of Nigeria. (RAESON) (8),30-31

Holman, J.P. (2010). Heat Transfer, New York, United States: Mc Graw Hill Company.

Karunesh Kant, Shukla A., Atul S., Anil K, and Anand J (2016):

Thermal energy storage based solar drying systems: A review, Journal of Innovative Food Science and Emerging Technologies 34: 86-99, www.elsevier.com/locate/ifset

Kumar, A., and Shukla, S.K. (2015) A Review on Therma Energy Storage Unit for Solar Thermal Power Plant Application. Energy Procedia (74), 462-469.
Presley, M. A., and Christensen, P. R.(1996) The Effect of Bulk Density and Particle Shape on the Thermal Conductivity of Particulate Materials Under Martian Atmospheric Pressures. Lunar and Planetary Science journal, 27:1057 1996LPI....27.1057P

Rajeshwari, N., and Ramalingam, A. (2012). Low-cost material used to construct Effective box type solar dryer. Archives of Applied Science Research, 4 (3), 1476-1482 retrieved from http://scholarsresearchlibrary.com/archive.html

Reddy Prasad, D.M., Senthilkumar, R., Govindarajan Lakshmanarao, Saravanakumar Krishnan and Naveen Prasad B.S. (2019) A critical review on thermal energy storage materials and systems for solar applications AIMS Energy, 7(4), 507-526. doi:10.3934/energy.2019.4.507

Richard, D. O'Brien (2009) Fats and Oils: Formulating and Processing for Applications,

Third Edition by CRC press. 